\title{
Riscos em operações de troca no agronegócio: análise de modelo de gerenciamento de riscos para cooperativas
}

\author{
Risks of barter in agribusiness: an analysis of a risk management model for cooperatives
}

\begin{abstract}
Resumo
Nas operações de troca os agentes envolvidos são os produtores, as cooperativas e as empresas fornecedoras (Traders). As cooperativas atuam como intermediárias permitindo a aproximação entre os agentes e minimizando o risco de crédito. O objetivo desta pesquisa é analisar um modelo de gerenciamento dos riscos dessas operações. Ele foi desenvolvido com base na literatura sobre protocolos de gerenciamento de riscos, resultando em um modelo híbrido que contempla a identificação, análise e possíveis estratégias de respostas aos riscos. O modelo foi aplicado em uma cooperativa agroindustrial e contemplou as perspectivas dos agentes envolvidos. Foi utilizada análise de conteúdo de entrevistas e documentos para identificação dos riscos. Também foi feita a análise dos riscos quanto à sua probabilidade de ocorrência e impacto, permitindo assim a criação de matrizes de riscos. Com isso, foi possível avaliar as estratégias de respostas aos riscos nas perspectivas do produtor, cooperativa e Trader. Os resultados contribuem para a disseminação da prática do gerenciamento de riscos em operações de troca no agronegócio.
\end{abstract}

Palavras-chave: Modelos de gerenciamento de riscos, agronegócio, cooperativas, operações de barter.

\begin{abstract}
On barter operations the involved agents are producers, cooperatives and Traders (suppliers). In this context cooperatives play a role of brokers allowing an approaching among agents and minimizing credit risks. The goal of this research is to assess a risk management model for barter operations. It was developed based on literature on protocols of risk management, resulting on a hybrid model which provides identification, assessment and possible responses to deal with risks. The model was applied on an agro industrial cooperative considering the perspectives of the involved agents. Content analysis of interviews and documents was used in the research aiming at identification of risks. Then, it was made an assessment of risks regarding their occurrence probability and impact on results, thus allowing the building of risk matrices for the agents. So, it was possible to assess strategies for risk responses considering the perspectives of producers, cooperative and Trader. Results contribute for a dissemination of risk management practices for barter in agribusiness.
\end{abstract}

Keywords: Risk management models, agribusiness, cooperatives, barter operations.

Altevir Costa Sanches ${ }^{\mathrm{I}}$, Vilmar Rodrigues Moreira ${ }^{\mathrm{II}}$, Carlos Augusto Candeo Fontanini ${ }^{\mathrm{III}}$

${ }^{\text {I }}$ Cooperativa Agropecuária e Industrial de Mandaguari, altevircs@ hotmail.com.

II Universidade Católica do Paraná, vilmar.moreira@pucpr.br.

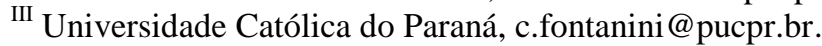




\section{Introdução}

O agronegócio desempenha um papel fundamental no desenvolvimento da economia brasileira, promovendo a criação de empregos, apoiando positivamente a balança comercial com a força e magnitude de suas exportações e influenciando substancialmente na composição do Produto Interno Bruto do país

(MOREIRA; KURESKI; VEIGA, 2016). Neste contexto, o crédito rural é essencial para a viabilização das atividades do agronegócio, sobretudo para os pequenos e médios produtores.

O crédito rural abrange recursos destinados a custeio, investimento e comercialização. As suas regras, finalidades e condições estão estabelecidas no Manual de Crédito Rural (MCR), elaborado pelo Banco Central do Brasil. Essas normas são seguidas por todos os agentes que compõem o Sistema Nacional de Crédito Rural (SNCR), como bancos e cooperativas de crédito. Os créditos de custeio ficam disponíveis quando os recursos se destinam a cobrir despesas habituais dos ciclos produtivos, da compra de insumos à fase de colheita. Os de investimento são aplicados em bens ou serviços duráveis, cujos benefícios repercutem durante muitos anos. Os créditos de comercialização asseguram ao produtor rural os recursos necessários à adoção de mecanismos que garantam o abastecimento e levem o armazenamento da colheita nos períodos de queda de preços. Os financiamentos agropecuários tradicionais são concedidos para produtores rurais e cooperativas por meio de bancos oficiais, privados e cooperativas de crédito, com a finalidade financiar o custeio da produção e da comercialização de produtos agropecuários, bem como estimular os investimentos rurais, incluindo armazenamento, beneficiamento e industrialização dos produtos agrícolas.

Ao longo do tempo, segundo Belik (2015), Paraná Cooperativo (2016) e Ministério da Agricultura (BRASIL, 2016), o governo brasileiro tem procurado rever e redimensionar o papel do Estado no que se refere à agricultura, deixando de ser o maior financiador, regulador do mercado e controlador dos estoques físicos dos produtos. Por conseguinte, as modalidades de financiamento concedidas diretamente ao produtor têm sido cada vez mais escassas e outras modalidades têm surgido, principalmente, no mercado financeiro. Todavia, as opções de financiamento via mercado financeiro requerem capacitações específicas e uma estrutura gerencial adequada devido a sua complexidade e volumes negociados.

Outras possibilidades de concessão de crédito aos agricultores para compra de insumos agrícolas são aquelas realizadas com o fornecedor do insumo. De acordo com Silva (2012) há três modalidades mais usadas: crédito a vista / curto prazo - o pagamento do insumo ocorre antes do momento da colheita do produto; prazo safra - o pagamento do insumo ocorre após a colheita e; operação de troca (barter) - situação em que o pagamento do insumo se dá após a colheita com a entrega do produto, sem o pagamento em dinheiro.

As cooperativas exercem um papel importante para o desenvolvimento do agronegócio e dos empreendimentos de seus associados, provendo condições de desenvolvimento técnico, de mercado e de gestão (MOREIRA, FREIER e VEIGA, 2016). Além disso, é possível verificar que elas atuam não apenas como fornecedoras de insumos e compradoras da produção dos cooperados, mas também como intermediadoras financeiras em operações de troca e contratos de derivativos como mecanismos alternativos para o financiamento da produção. Nas operações de troca, em especial, foco deste estudo, identifica-se um alto grau de exposição ao risco de crédito, pois alguma das partes pode não honrar com o compromisso de entrega.

Assim, se a cooperativa se posiciona como intermediadora financeira em operações de troca, é necessário o estabelecimento de mecanismos de controle que a auxilie na decisão acerca de qual estratégia seguir para gerenciar os riscos destas operações. O objetivo deste artigo é analisar a aplicação de um modelo de gestão de riscos em operações de troca, abrangendo o mapeamento dos riscos e a proposição de estratégias de respostas a esses riscos.

\section{Referencial teórico}

Nesta seção são discutidas as estruturas de gestão de riscos, com ênfase nas diretrizes do modelo COSO e da ABNT ISO 31000:2018, e como estabelecer estratégias de respostas aos riscos. 


\subsection{Estruturas de gestão de riscos}

A essência da gestão de riscos, de acordo com a abordagem de Damodaran (2009), é o dualismo entre riscorecompensa. É a oportunidade de obter resultados positivos em riscos que devem ser explorados e, ao mesmo tempo, gerenciar a exposição a riscos que podem apresentar resultados indesejáveis. Para o autor: "a essência da gestão do risco não está em evitá-lo ou eliminá-lo, mas em decidir quais os riscos a explorar, quais os riscos a repassar aos investidores, e quais os que se deve evitar ou afastar como estratégia de hedge" (DAMODARAN, 2009, p. 362).

Há diversos modelos de gerenciamento de riscos que normalmente convergem para um mesmo objetivo: estabelecer um processo para balancear risco, oportunidade e valor (CHING, 2011; CHING e COLOMBO, 2013). Dentre eles, pode-se citar o modelo COSO (COSO, 2017), a Norma ISO 31000:2018 e o modelo de Famá, Cardoso e Mendonça (2002).

O modelo elaborado pelo Committee of Sponsoring Organizations (COSO) tem como premissa alinhar a gestão de risco com a estratégia adotada pela empresa, fortalecer as decisões em resposta aos riscos, identificar, administrar e reduzir riscos, aproveitar oportunidades e otimizar o capital para gerar valor às partes interessadas. Para isto foi estabelecido um modelo de diretrizes composto por categorias de objetivos estratégicos e componentes do gerenciamento de riscos (COSO, 2017). A dimensão Categorias de Objetivos é dividida em: organização;

- Estratégico: definido de acordo com a missão e com as metas da empresa, sendo a base da

- Operacional: refere-se às metas compostas para atingir a eficiência e eficácia da utilização dos recursos disponíveis;

- Comunicação: tem relação com confiabilidade das informações, ou seja, com a qualidade das informações contidas nos relatórios da empresa;

- Conformidade: está relacionado com o cumprimento das leis e regulamentos vigentes, sejam estes internos ou externos à organização.

Na dimensão Componentes do Gerenciamento de Riscos tem-se:

- Ambiente de Controle: base para os demais componentes, compreende as diretrizes para gerenciamento dos riscos e dos procedimentos de controle para toda a organização;

- Fixação de Objetivos: deve ser coerente com a missão e visão da organização, sendo realizada primeiramente no âmbito estratégico para, em seguida, abranger as demais áreas da empresa, com direcionamento voltado a evitar ou minimizar os riscos;

- Identificação de Eventos: fatores internos ou externos que sejam potencialmente geradores de riscos ou de oportunidades;

- Avaliação de Riscos: compreende a avaliação da probabilidade de ocorrência dos eventos identificados, assim como na análise dos possíveis impactos quanto ao alcance dos objetivos da organização;

- Resposta aos Riscos: considera o custo versus o benefício de definir um controle apropriado, a probabilidade de ocorrência e o impacto que os riscos avaliados causarão na organização, trazendo estes aos níveis tolerados;

- Atividades de Controle: atividades globais dentro da empresa que irão assegurar que as atividades de controle ou mitigação dos riscos sejam efetivadas; 
- Informações e Comunicações: divulgação para níveis organizacionais, inclusive investidores, sobre os riscos identificados e como estes devem ser gerenciados;

- Monitoramento: compreende o contínuo acompanhamento dos riscos e de suas atividades de controle (resposta aos riscos), de modo que, se identificada a necessidade de redirecionamento, estas sejam conduzidas às alterações na forma como se dá o gerenciamento dos riscos.

O modelo sugerido pela Norma ISO 31000:2018, denominado de Processo de Gestão de Riscos, apresentado na Figura 1, considera que a gestão de riscos deve fazer parte do processo de gestão, da cultura e prática, adaptada aos processos de negócio da organização.

Figura 1 - Processo de Gestão de Riscos (Norma ISO 31000:2018)

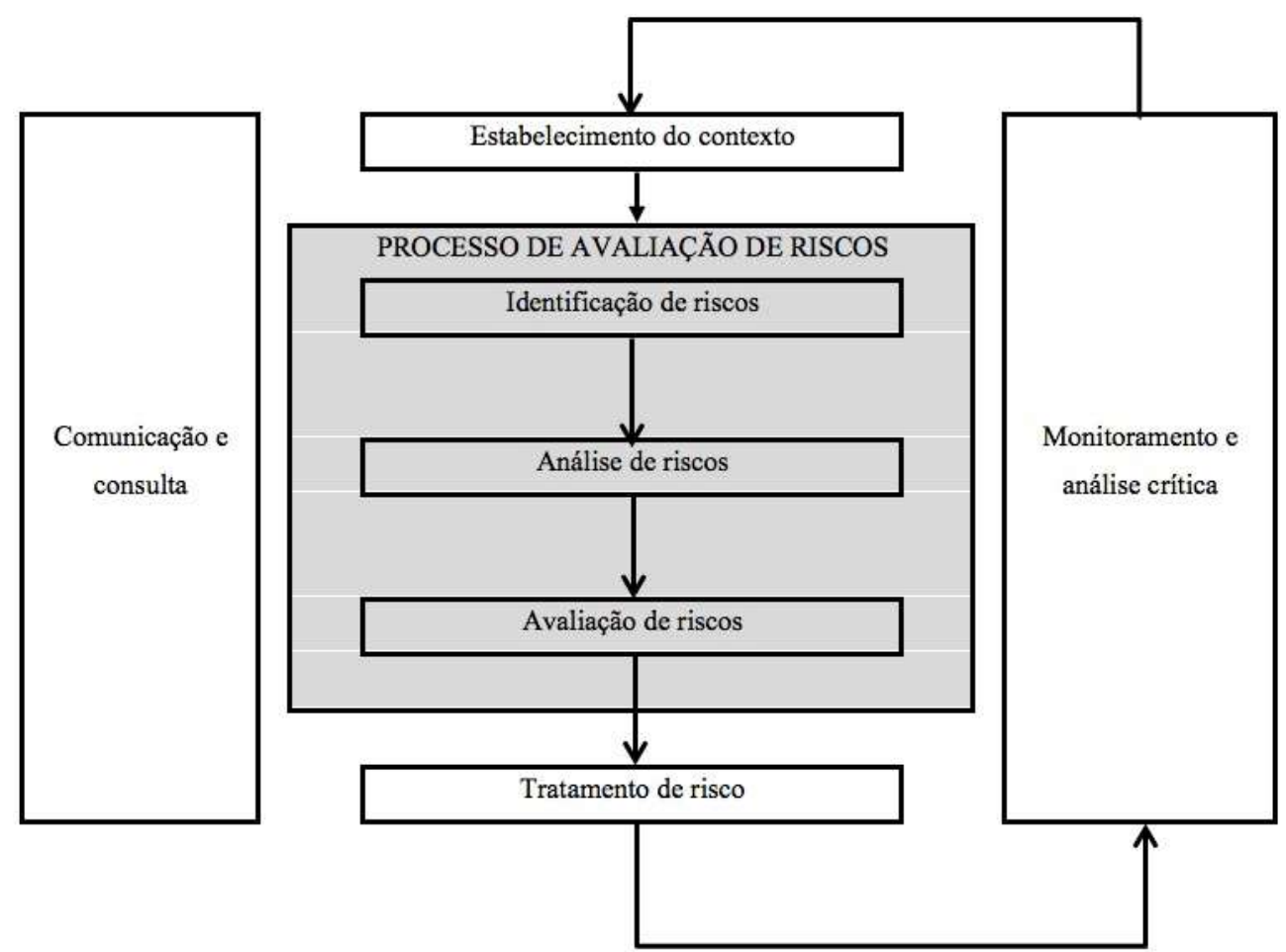

Fonte: adaptado de ABNT NBR ISO 31000 (2018)

O modelo ISO 31000 é composto por cinco elementos:

i. Comunicação e consulta: deve ocorrer em todas as etapas para assegurar a implementação do processo de gestão de risco e a compreensão dos fundamentos das ações a serem tomadas pelas partes interessadas;

ii. Estabelecimento do contexto: compreende o ambiente externo, o ambiente interno e o processo de gestão de riscos. Assim, deve ser estabelecida a articulação dos objetivos e a definição dos parâmetros externos e internos da organização para o gerenciamento de riscos bem como o escopo e os critérios de risco para o restante do processo. Para o contexto externo é importante assegurar que os objetivos e as preocupações das partes interessadas externas sejam considerados no desenvolvimento dos critérios de risco. No contexto interno deve haver alinhamento com a cultura, processos, estrutura e estratégia da organização.

iii. Processo de avaliação de riscos, subdivida em identificação de riscos, a análise de riscos e a avaliação dos riscos. 
iv. Tratamento de riscos compreende a seleção e implementação de uma ou mais opções para responder aos riscos.

v. Monitoramento e análise crítica: realizado de modo periódico ou em resposta a um evento específico, deve ser planejado como parte do processo de gestão de riscos e envolve verificação regular. Ainda, deve abranger todos os aspectos da gestão de riscos a fim de garantir a eficiência e eficácia dos controles internos; aprimorar o processo de gestão; detectar mudanças no contexto externo e interno, incluindo alterações nos critérios de risco e; identificar riscos emergentes.

O modelo denominado de Gestão Integrada do Risco, proposto por Famá, Cardoso e Mendonça (2002), é apresentado na Figura 2. Para os autores o modelo está fundamentado em uma estrutura gerencial baseada em uma visão global dos riscos. As pessoas envolvidas no processo de tomada de decisão devem basear-se nessa estrutura para analisar as questões relacionadas aos riscos que a organização está exposta.

Figura 2 - Estrutura da Gestão Integrada do Risco

\begin{tabular}{|c|c|c|}
\hline \multicolumn{3}{|c|}{ GESTĀOINTEGRADADORISCO } \\
\hline $\begin{array}{l}\text { Visăo Integrada dos Riscos } \\
\text { Tipos de Riscos: } \\
\text { a) Estratégico; } \\
\text { b) Operacional; } \\
\text { c) Legal; } \\
\text { d) Financeiro. } \\
\text { Fatores de Influência: } \\
\text { a) Ambiente Extemo; } \\
\text { b) Ambiente Interno. } \\
\text { Grau de Impacto nos Negócios: } \\
\text { a) Alto; } \\
\text { b) Médio; } \\
\text { c) Baixo. }\end{array}$ & $\begin{array}{l}\text { Gerenciamento do Risco } \\
\text { a) Mapear os riscos por ordem de } \\
\text { prioridade e tempo de ocorrên- } \\
\text { cia; } \\
\text { b) Dimensionar a probabilidade } \\
\text { de ocorrência; } \\
\text { c) Estabelecer uma relação de } \\
\text { causa e efeito entre o risco e o } \\
\text { negócio; } \\
\text { d) Montar a matriz de decisāo em } \\
\text { relação aos fatores de probabi- } \\
\text { lidade, grau de impacto, tempo, } \\
\text { estimativas e possiveis solu- } \\
\text { çōes. }\end{array}$ & $\begin{array}{l}\text { Processo Decisório sobre Risco } \\
\text { Passos: } \\
\text { 1) Estabelecer em comitê quais ris- } \\
\text { cos devem ser priorizados: } \\
\text { 2) Reportar a alta administração } \\
\text { com as possiveis soluçōes; } \\
\text { 3) Estabelecer as ferramentas para } \\
\text { controle; } \\
\text { 4) Implantar o acompanhamento } \\
\text { gerencial }\end{array}$ \\
\hline
\end{tabular}

Fonte: Famá, Cardoso e Mendonça (2002).

Este modelo é composto por três processos. O primeiro é a "visão integrada dos riscos", no qual se deve analisar os fatores internos e externos que influenciam na ocorrência dos riscos e, de maneira preliminar, o seu impacto nos negócios a fim de determinar medidas de controle. O segundo processo, "gerenciamento do risco", compreende a organização e identificação dos riscos de acordo com as probabilidades de ocorrência, causa e efeitos para analisar com maior profundidade os impactos do risco para a organização e, então, possíveis soluções. O terceiro processo, "processo decisório sobre o risco", consiste em definir quais riscos são prioritários e as ferramentas para a gestão destes riscos.

\subsection{Estratégias de respostas aos riscos}

Segundo Ehrlich (2004) o risco é um conceito tridimensional que envolve o evento (ganho ou perda), a probabilidade de ocorrência e o tempo. Em todos os modelos de gestão de riscos citados na seção anterior, um passo fundamental é a identificação e avaliação dos riscos. Uma vez identificados, eles devem ser qualificados ou quantificados quanto à sua probabilidade de ocorrência e impacto (efeito) nos resultados. Para alguns riscos sua quantificação é possível se houver uma base histórica de registros que possibilite o ajustamento de distribuições de probabilidade para avaliação das chances de ocorrência. Isso também vale para a avaliação do impacto na organização, que normalmente é avaliado em termos financeiros. No entanto, quando não há como atribuir valores objetivos para as probabilidades de ocorrência e impactos financeiros dos riscos, é comum o analista de risco atribuir classificações em classes, como citado abaixo (IFAC, 1999; DAMODARAN, 2009; PADOVEZE e BERTOLUCCI, 2013): 
I) Probabilidade de ocorrência

- Baixa: a ocorrência do risco pode ser considerada improvável ou reduzida em um determinado período de tempo, face ao raro ou nenhum registro da sua ocorrência.

- Média: existe uma probabilidade moderada de ocorrência, podendo ocorrer mais de uma vez em um determinado período de tempo, logo o risco é possível. de tempo.

- Alta: o risco é iminente ou provável porque sua ocorrência é frequente em determinado período

II) Impacto (efeito)

- Baixo: o impacto do risco é irrelevante para a organização, tanto em termos de custo, quanto de prazos, podendo ser solucionado ou aceito (passivamente),não demandando o planejamento de respostas.

- Médio: o impacto do evento de risco é moderado e necessita de um gerenciamento mais acurado, sob pena de prejudicar os resultados do negócio e/ou seus objetivos operacionais e estratégicos.

- Alto: o impacto do evento de risco é elevado e, no caso de não existir uma interferência direta, imediata e precisa, os resultados do negócio e/ou seus objetivos operacionais e estratégicos serão seriamente comprometidos.

Em alguns tipos de riscos há meios eficientes de proteção ofertados pelo mercado ou pelo governo, entretanto, para outros tipos, o produtor se torna o tomador exclusivo do risco (MOREIRA, SOUZA e DUCLÓS, 2014). Após os riscos serem identificados e analisados, considerando suas probabilidades de ocorrência e impactos, deve-se definir a estratégia de respostas ordenadas quanto ao custo e benefício. As estratégias gerais envolvem (BORGERTH, 2006; COSO, 2007; OZAKI, 2007, DIAS, 2008; DAMODARAN, 2009; DIAS, 2010; PADOVEZE e BERTOLUCCI, 2013; LOYOLA, MOREIRA e VEIGA, 2016):

- Eliminar/Evitar: altera o escopo do evento a fim de eliminar a causa do risco, reduzindo a zero sua probabilidade de ocorrência. Estrategicamente opta-se por não se envolver ou abandonar determinada atividade.

- Transferir/Compartilhar: passa a responsabilidade e efeitos do risco para uma terceira parte, como por exemplo uma seguradora, geralmente na forma de subcontrato. Contudo o risco não é eliminado e deve ser monitorado. Deve-se considerar o custo de transferir o risco em relação ao potencial benefício dessa operação.

- Mitigar/Reduzir: compreende ações antecipadas para a redução da probabilidade de ocorrência e/ou do efeito do risco para um nível de tolerância aceitável pela empresa. Quando a mitigação/redução não pode ser plena, deve-se utilizar estratégias de aceitação/controle. O pressuposto que orienta a mitigação é o fato do seu custo não ser superior aos efeitos da ocorrência dos riscos.

- Aceitar/Controlar: é a decisão de não realizar nenhuma ação preventiva em resposta ao risco porque esta não foi identificada ou porque o seu custo é maior que o benefício esperado. Também pode ocorrer quando o risco já está alinhado com a tolerância de sua aceitação. Em todas essas situações deve-se haver monitoramento e/ou controle do risco. A aceitação/controle pode ser implantada de maneira ativa ou passiva. A aceitação/controle ativa compreende planejamento de ações contingenciais para serem executadas caso o risco ocorra. A passiva compreende a não definição de ações contingenciais, ou seja, aguarda a ocorrência do risco para definir a resposta (ação). 
A Figura 3 apresenta as estratégias sugeridas em relação aos riscos de acordo com a probabilidade de ocorrência e seu efeito.

Figura 3 - Matriz de Estratégias de Respostas aos Riscos

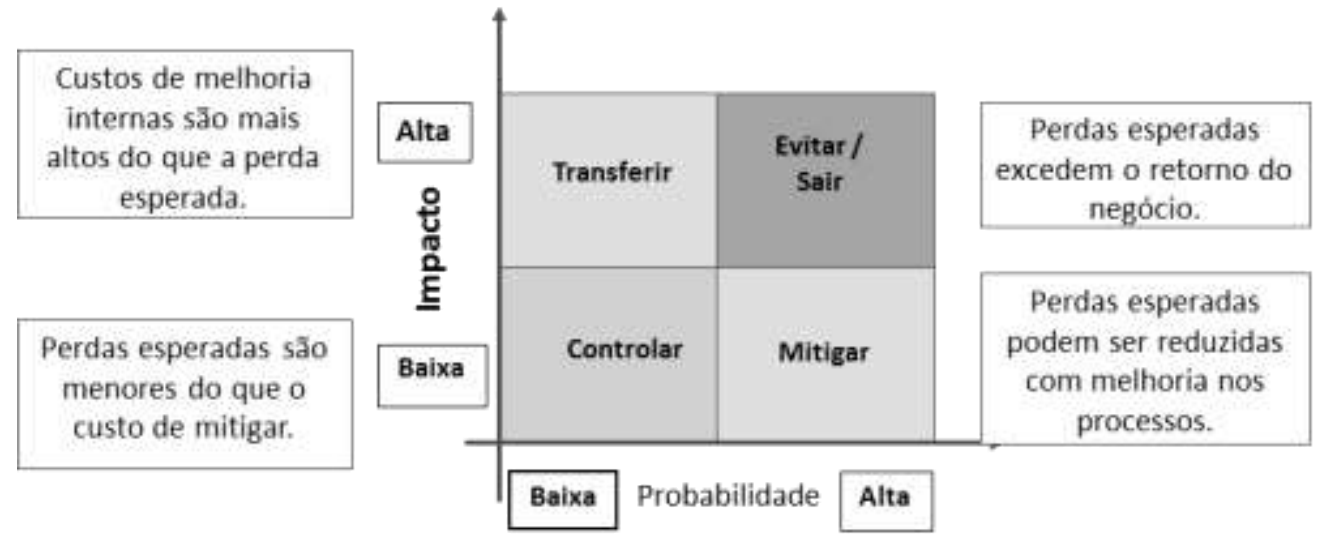

Fonte: Borgerth (2006).

Segundo essa matriz, as estratégias gerais de respostas aos riscos tem relação direta com o grau de probabilidade de ocorrência e o impacto, tendo-se que levar em consideração a relação custo-benefício de cada estratégia.

\section{Procedimentos metodológicos}

O objetivo desta pesquisa é apresentar a aplicação, em uma cooperativa agroindustrial, de um modelo de gerenciamento dos riscos envolvidos nas operações de troca no agronegócio, denominado de GROT (Gestão de Riscos em Operações de Troca). O modelo é híbrido e baseado na Estrutura Integrada para o Gerenciamento de Riscos Corporativos (cubo do COSO), no Processo de Gestão de Riscos (Norma ISO 31000:2018) e no Modelo de Gestão Integrada do Risco proposto por Famá, Cardoso e Mendonça (2002). A Figura 4 apresenta o modelo GROT, que contempla a análise do contexto, identificação e análise dos riscos, definição de estratégias de respostas, implantação e acompanhamento.

Figura 4 - Modelo de Gestão de Riscos em Operações de Troca - GROT

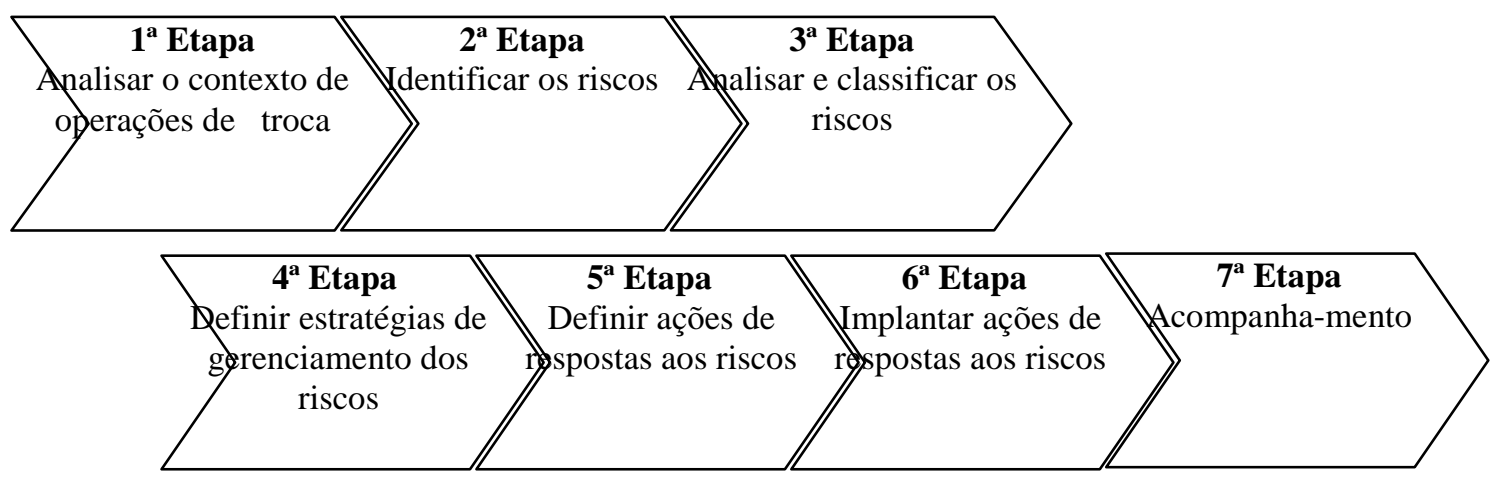

Fonte: Elaboração própria.

Para a análise da aplicação do modelo foi desenvolvido um estudo de caso único. A pesquisa foi realizada em uma Cooperativa Agroindustrial, tendo como unidade de análise as áreas de Suprimentos (insumos) e de Comercialização de grãos, as quais estão diretamente ligadas com a operacionalização dos contratos nas operações de troca. Os resultados alcançados são atinentes, exclusivamente, ao caso estudado e ao período em que os dados se referem $(2014,2015,2016)$. O estudo de caso foi descritivo e explicativo. 
Como fonte de evidências foram utilizadas entrevistas semiestruturadas, bem como, relatórios da empresa (análise documental). O roteiro de perguntas das entrevistas foi elaborado a partir de duas fontes de dados preliminares: a pesquisa bibliográfica e a análise dos relatórios da empresa para obter dados mais específicos sobre gerenciamento de riscos nas operações de troca. Cabe ressaltar que o roteiro de perguntas foi elaborado de acordo com o entrevistado (cooperado, colaborador e profissional de mercado), que atua direta ou indiretamente, com o objeto de estudo e que possui experiência em operações de troca. Os entrevistados se caracterizam em três grupos:

- Produtores cooperados que efetuam operações de troca. Esses cooperados são os que possuem maior experiência neste tipo de operação, ou seja, foram os primeiros que fizeram esse tipo de operação na Cooperativa;

- Colaboradores da Cooperativa Agroindustrial que atuam diretamente com este tipo de operação;

- Profissional do mercado, que atua em uma Trader que a Cooperativa opera.

A análise documental foi feita em relatórios da empresa. Alguns relatórios consultados são de natureza gerencial, como relatório de contratos e de recebimento de grãos; outros são de natureza referente ao quadro social da Cooperativa, Relatório da Administração. Esses relatórios foram fontes de dados iniciais sobre o caso estudado, pois contribuíram para o levantamento quantitativo de informações sobre os contratos de troca.

Os dados da pesquisa foram interpretados considerando o contexto organizacional da Cooperativa em estudo. Como se trata de uma técnica de pesquisa qualitativa, os dados foram tratados usando a análise do conteúdo e a triangulação. De acordo com Martins (2006), a triangulação é a combinação de diversas fontes de coleta de dados qualitativos e o uso de diferentes técnicas de análise destes dados para aumentar a confiabilidade do estudo de caso. Isso proporciona uma descrição mais detalhada do evento estudado e limita os vieses pessoais e metodológicos quando é usado apenas uma única fonte de dados e único método de análise. A comparação dos resultados das entrevistas em conjunto com os documentos da empresa e a base teórica, compreende a triangulação que o estudo de caso requer para aumentar sua confiabilidade.

Assim, a triangulação foi realizada com os dados coletados por meio de entrevistas com os três grupos diferentes de entrevistados e de relatórios da empresa, com a finalidade de confirmar ou complementar informações sobre a pesquisa (riscos nas operações de troca). Isto reduziu os possíveis vieses metodológicos do estudo de caso.

\section{Apresentação e Análise dos Resultados}

A análise de conteúdo das entrevistas e documentos da Cooperativa permitiu a avaliação das 5 primeiras etapas do modelo GROT. A apresentação e discussão dos resultados da pesquisa são feitas nesta seção de acordo com as etapas do modelo.

\subsection{Análise do contexto $-\mathbf{1}^{\mathrm{a}}$ etapa do modelo GROT}

Para os entrevistados a operação de contratos de troca é uma modalidade de alavancar crédito e financiamento para os agricultores, Cooperativa e Trader. Para os agricultores a troca é uma forma de crédito para comprar insumos, principalmente em períodos de crise quando este se torna escasso, e tem a vantagem de travar/fixar o preço do grão, pois mitiga os riscos de a rentabilidade da produção ser afetada por quebra de safra ou baixa do preço no momento da colheita, por exemplo. Em outras palavras, mantém o custo de produção porque determina e é garantido o custo fixo de sacas por área. A Cooperativa entende a troca como uma modalidade de hedge para o produtor, sendo uma modalidade de financiamento para ele. Para a Cooperativa é tanto uma modalidade de concessão de crédito (ao produtor) quanto de obtenção de crédito (financiamento) obtido da Trader. Para essa última, uma modalidade de concessão de crédito. Historicamente, quando a Cooperativa iniciou a realização de contratos de operações de troca, estes eram somente de grãos e fertilizantes. Ao longo do tempo expandiu para defensivos e sementes. 
Na negociação da operação com o agricultor existem duas opções: (i) travar as duas pontas (preço dos insumos e dos grãos), gerando a proporcionalidade ou (ii) travar somente o insumo, deixando o grão para fechamento posterior. Normalmente é orientado o travamento das duas pontas, pois se realizar a fixação do preço do grão em momento diferente pode haver interferência na proporção grão/insumos. Essa variação pode por influenciar na rentabilidade da troca para o agricultor. Para o agricultor que opta pela operação de troca e deixa para fixar o preço do grão em momento posterior, esta operação é limitada entre 30 e 35 sacas por hectare (sc/ha). Essa quantidade de sacas se refere ao custo de produção e, historicamente, não há registros frequentes de lavouras com quebra abaixo de $30 \mathrm{sc} / \mathrm{ha}$. Normalmente o produtor também adquire o seguro agrícola direcionado a culturas permanentes e temporárias, como mecanismo de proteção em caso de frustação da safra. Nas entrevistas com os colaboradores da cooperativa foi comentado que nas últimas safras o governo federal não efetuou o pagamento da subvenção do seguro. Neste caso, algumas seguradoras assumiram esse valor e quando não, o produtor tinha a opção de pagar o valor total ou a parcela não subvencionada do seguro. Além do seguro, na efetivação da operação de troca, emite-se a Cédula de Produto Rural (CPR) para garantir a operação, a qual deve ser registrada em cartório.

Por outro lado, a Cooperativa compra os insumos com prazo safra, financiando por meio da própria Trader ou via agente financeiro. Em seguida, realiza a venda do grão para a mesma data futura, para não haver descasamento do prazo no fluxo financeiro.

Assim, existem algumas maneiras de operacionalizar as trocas:

- A Cooperativa compra os insumos em Reais, da Trader; faz a venda do grão para Trader, também em Reais.

- A Cooperativa compra os insumos em Reais, da Trader; faz a venda do grão para Trader, em Dólar.

- A Cooperativa compra os insumos em Dólar, daTrader; faz a venda do grão para Trader, em Reais.

- A Cooperativa compra os insumos em Dólar, daTrader; faz a venda do grão para Trader, também em Dólar.

E, por sua vez, a Trader compra o grão da Cooperativa e exporta-o ou processa-o.

A

Tabela 1 mostra a proporção de contratos e de operações de troca em relação ao recebimento de grão (em sacas), segregado nas principais commodities objeto de contratos (milho e soja) e nas divisões agrícolas do Cerrado (Estado de Goiás) e Estado do Paraná, onde a Cooperativa atua.

Tabela 1 - Recebimento, contratos e trocas

\begin{tabular}{lllllll}
\hline Divisão & Produto & $\begin{array}{l}\text { Recebimento } \\
\text { (A) }\end{array}$ & $\begin{array}{l}\text { Contratos } \\
(\text { B })\end{array}$ & $\begin{array}{l}\text { Participação } \\
\text { (B/A) }\end{array}$ & $\begin{array}{l}\text { Troca } \\
\text { (D) }\end{array}$ & $\begin{array}{l}\text { Participação } \\
\text { (D/A) }\end{array}$ \\
\hline
\end{tabular}

\begin{tabular}{|c|c|c|c|c|c|c|}
\hline \multicolumn{7}{|c|}{ Safra 2014/2015 } \\
\hline Cerrado & Milho & 2.968 .603 & 540.015 & $18,2 \%$ & 486.014 & $16,4 \%$ \\
\hline Paraná & Milho & 2.715 .098 & 134.023 & $4,9 \%$ & 134.023 & $4,9 \%$ \\
\hline Total & & 5.683 .701 & 674.038 & $11,9 \%$ & 620.037 & $10,9 \%$ \\
\hline Cerrado & Soja & 3.614 .038 & 1.261 .127 & $34,9 \%$ & 1.071 .958 & $29,7 \%$ \\
\hline Paraná & Soja & 6.003 .426 & 943.029 & $15,7 \%$ & 660.120 & $11,0 \%$ \\
\hline Total & & 9.617 .464 & 2.204 .156 & $22,9 \%$ & 1.732 .078 & $18,0 \%$ \\
\hline
\end{tabular}




\section{Safra 2015/2016}

\begin{tabular}{lllllll} 
Cerrado & Milho & 3.905 .000 & 1.005 .995 & $25,8 \%$ & 717.536 & $18,4 \%$ \\
Paraná & Milho & 3.491 .100 & 717.536 & $20,6 \%$ & 804.796 & $23,1 \%$ \\
\hline Total & & 7.396 .100 & 1.723 .531 & $23,3 \%$ & 1.522 .332 & $20,6 \%$ \\
\hline Cerrado & Soja & 4.069 .787 & 1.823 .697 & $44,8 \%$ & 1.340 .886 & $32,9 \%$ \\
Paraná & Soja & 4.472 .684 & 2.062 .902 & $46,1 \%$ & 1.340 .886 & $30,0 \%$ \\
\hline Total & & 8.542 .471 & 3.886 .599 & $45,5 \%$ & 2.681 .772 & $31,4 \%$ \\
\hline
\end{tabular}

Fonte: Elaboração própria.

É possível constatar as seguintes características do contexto das operações:

- As operações de troca representam parcela significativa de todos os contratos agrícolas firmados entre Agricultor e Cooperativa;

- A soja é o produto com maior percentual de contratos;

- Na divisão Cerrado a prática de realizar contratos agrícolas, inclusive de troca, é mais disseminada entre os agricultores. Isto se justifica pela predominância de propriedades latifundiárias, onde os agricultores procuram utilizar mecanismos de proteção dos custos da safra, investem mais em tecnologias agrícolas, possuem uma estrutura administrativa para a propriedade e são mais aptos em buscar e aceitar inovações;

- Na divisão Paraná as propriedades agrícolas são, predominantemente, de pequeno ou médio porte. Esta característica do tamanho da propriedade reflete na postura do agricultor. Ou seja, o agricultor paranaense usa mecanismos mais tradicionais ou são menos propensos em buscar por novas tecnologias de produção e mecanismos de proteção da safra. Mas nota-se que da safra 2014/15 para a safra 2015/16 houve um aumento nos contratos, inclusive de operações de troca. Essa mudança foi decorrente de uma campanha de divulgação e conscientização da importância e dos benefícios dos contratos agrícolas, em especial operações de troca, realizada pela Cooperativa junto aos seus cooperados agricultores.

Este contexto evidencia que as operações de troca ainda têm um vasto campo de crescimento entre os agricultores cooperados, bem como, internamente, na Cooperativa, de modo que esta estruture melhor a sua gestão de riscos neste tipo de operação. Tal adequação requer, inclusive, o desenvolvimento e institucionalização de uma metodologia de gerenciamento de riscos que atenda tanto o produtor quanto à Cooperativa.

Algumas medidas de gerenciamento de riscos já são tomadas por parte da Cooperativa e incentivadas para o produtor. Entre essas medidas destaca-se: dos grãos;

- Incentivo para o produtor fazer o contrato de operação de troca travando o preço dos insumos e

- A operação é limitada a $35 \mathrm{sc} / \mathrm{ha}$ - este fator é com base no histórico de produtividade dos produtores na área de atuação da cooperativa;

- Uso do seguro agrícola;

- Emissão da CPR como garantia da operação de troca;

- Uso do prazo safra no contrato com o produtor e com o contrato a Trader, para não afetar o fluxo financeiro decorrente de prazos diferentes de liquidação.

Embora a Cooperativa adote essas medidas, foi possível verificar que os colaboradores possuem uma compreensão macro, com menor detalhamento, sobre o que é, de fato, gerenciamento de riscos. Para eles os 
riscos deste tipo de contrato são divididos em grandes grupos: mercado, produção, contrato, sistêmico e cambial, os quais estão gerenciados pelas medidas adotadas no momento.

\subsection{Identificação - $2^{\mathrm{a}}$ etapa do modelo GROT}

Os riscos foram inicialmente identificados com base na literatura e, em seguida, verificados por meio das entrevistas com produtores, Cooperativa e Trader. A categorização dos riscos foi feita quanto à sua natureza (mercado, financeiro e operacional), como sugere Famá, Cardoso e Mendonça (2002) e considerados quanto à temporalidade de análise na perspectiva de longo prazo. $\mathrm{Na}$ análise de conteúdo das entrevistas e documentos, as unidades de análise foram os agentes estudados e os riscos. Cada grupo de risco foi segregado em tipos de riscos (categorização temática). A Tabela 2 apresenta os riscos que foram identificados por meio do seu agrupamento e origem.

Tabela 2 - Mapeamento dos riscos

\begin{tabular}{lll}
\hline GRUPO & TIPO & ORIGEM \\
\hline \multirow{2}{*}{ RISCO DE MERCADO } & Mercado/Preço & Mercado de Commodities \\
& Sistêmico & Mercado de Commodities \\
\hline \multirow{2}{*}{ RISCO FINANCEIRO } & Crédito & Sistema Financeiro \\
& Base & Custo de Transporte \\
& Cambial & Sistema Financeiro \\
& Liquidez & Sistema Financeiro \\
\hline \multirow{3}{*}{ RISCO OPERACIONAL } & Contrato & Sistema Financeiro \\
& Produção & Operacionalização do contrato \\
& Climático & Fatores tecnológicos \\
& Controle Administrativo & Clima \\
& Conhec. Téc. Operações de Troca & Operacionalização do contrato e \\
& Fitossanitário & Pessoas \\
& Pessoal & Pessoas e doenças \\
\hline
\end{tabular}

Fonte: Elaboração própria.

\subsection{Análise e classificação dos riscos $-3^{\mathrm{a}}$ etapa do modelo GROT}

$\mathrm{Na}$ análise de conteúdo das entrevistas e de registros documentais foi efetuada a codificação e categorização dos grupos e tipos de riscos quanto à sua probabilidade de ocorrência e impacto para o negócio na perspectiva de cada agente (produtor, Cooperativa e Trader). O cruzamento da probabilidade de ocorrência e impacto, classificados em classes (baixo, médio e alto) conforme sugerem IFAC (1999), Damodaran (2009) e Padoveze e Bertolucci (2013), possibilitou a construção das matrizes de risco que representam as percepções dos agentes.

Figura 5, e a Figura 7 apresentam as matrizes de risco do produtor, Cooperativa e Trader, respectivamente.

Os quesitos que nortearam a classificação da probabilidade e do impacto em baixo, médio ou alto foram específicos para cada tipo de risco identificado e para cada agente. Isto ocorreu porque foi necessário identificar as especificidades de ocorrência de cada risco bem como do seu efeito no agente em análise. 


\section{Figura 5 - Matriz de risco do produtor}

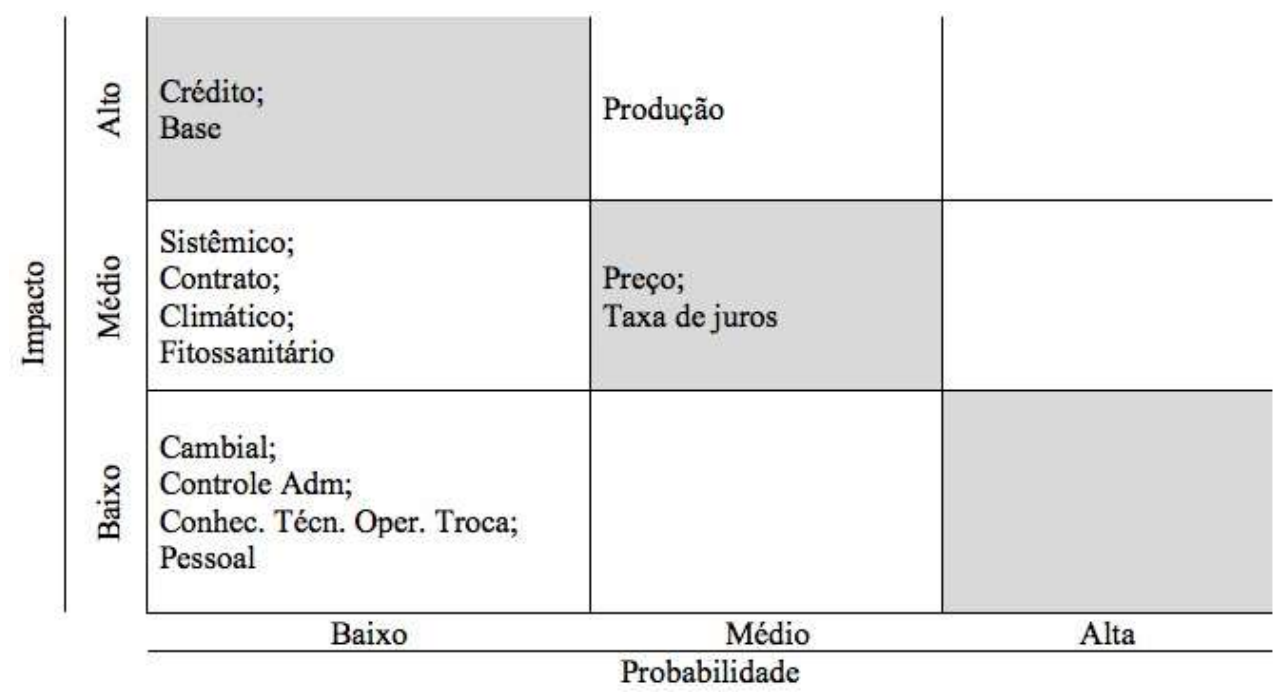

Fonte: Elaboração própria.

Figura 6 - Matriz de risco da cooperativa

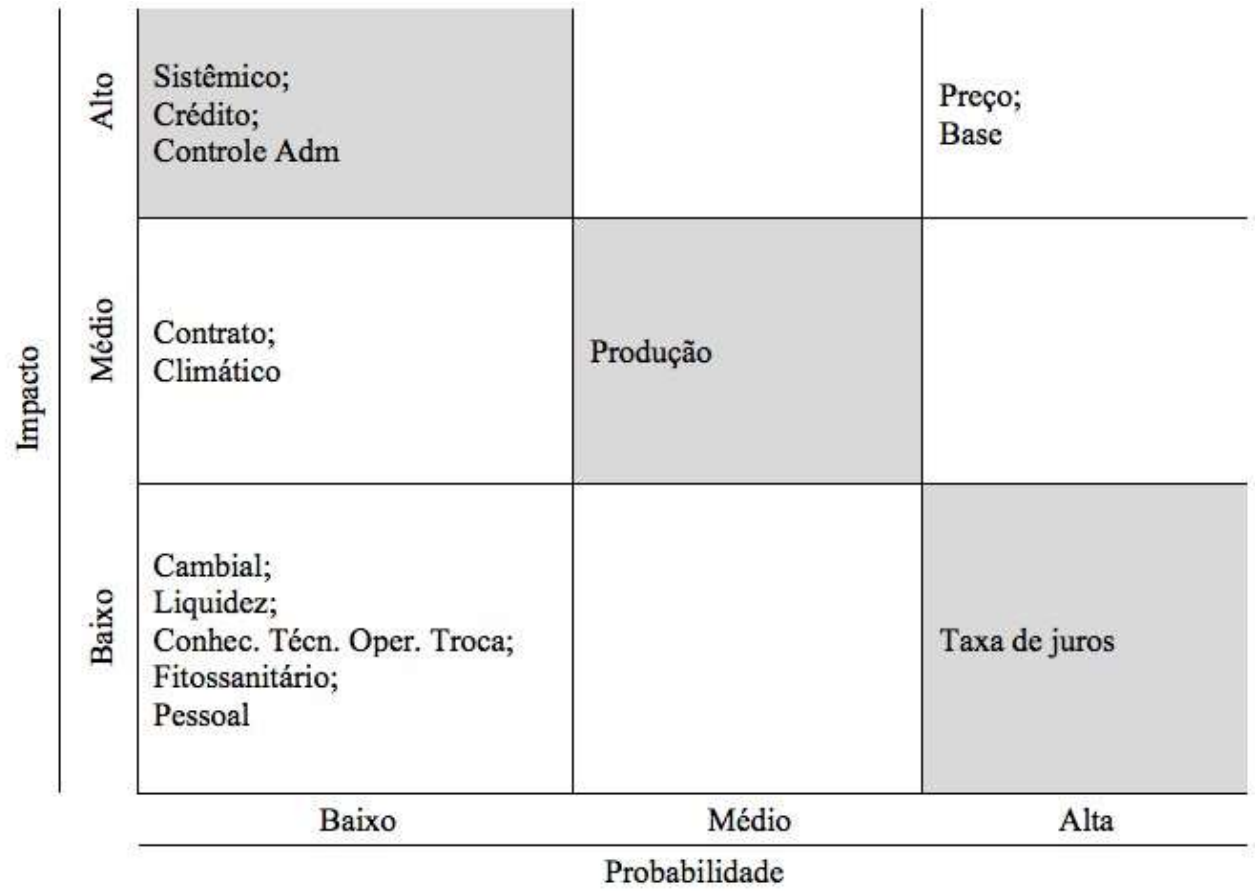

Fonte: Elaboração própria. 
Figura 7 - Matriz de risco da Trader

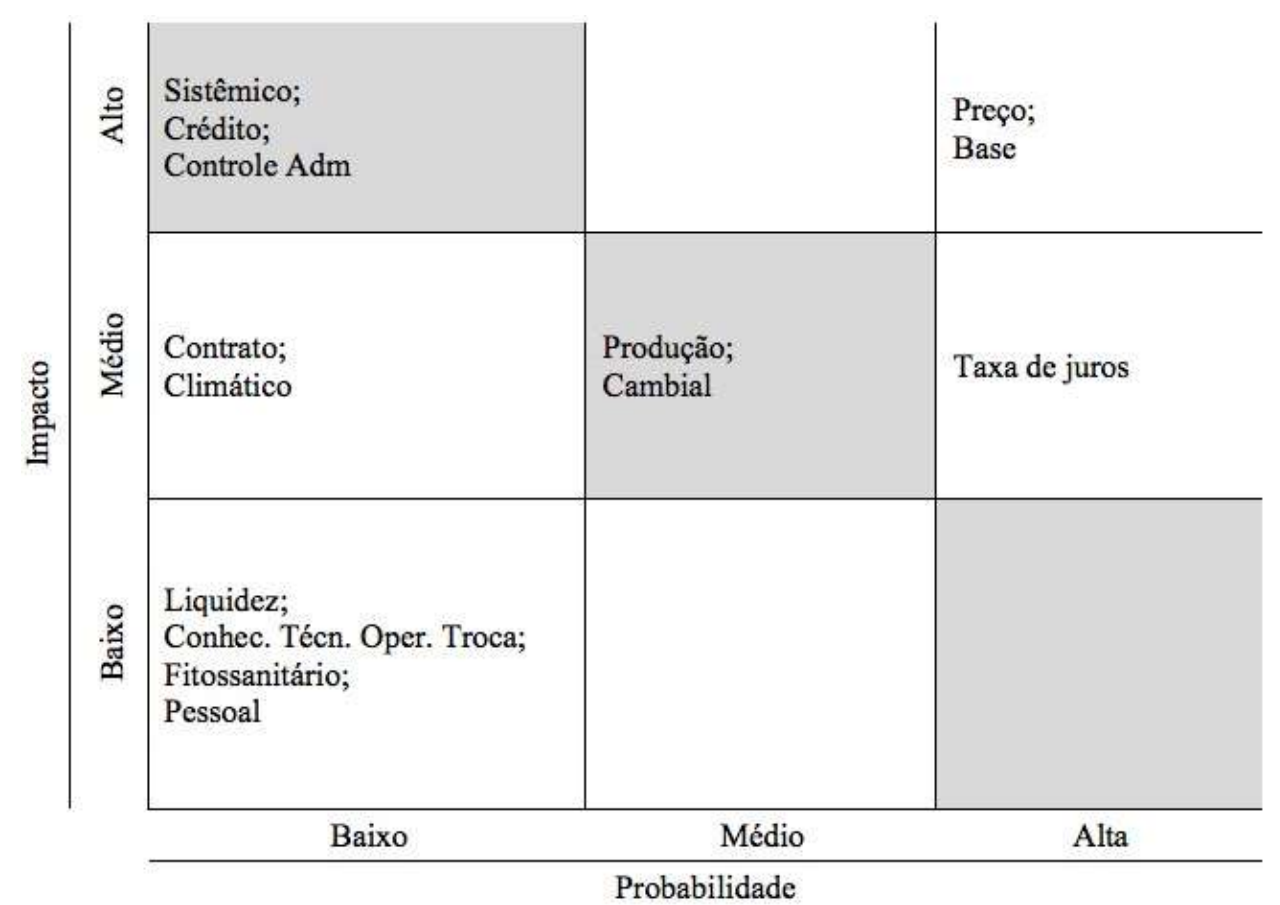

Fonte: Elaboração própria.

\subsection{Estratégias de gerenciamento e respostas aos riscos $-4^{\mathrm{a}}$ e $5^{\mathrm{a}}$ etapas do modelo GROT}

As estratégias de gerenciamento e respostas aos riscos são definidas de acordo com a relação custo/benefício e relações de probabilidade $\mathrm{x}$ impacto, identificadas na matriz de riscos. Essas relações também permitem definir qual deve ser a priorização das ações a serem tomadas. Por exemplo, um risco classificado com alta probabilidade de ocorrência e impacto, deverá receber maiores esforços e recursos para ações de respostas, sejam elas de mitigação, transferência ou outra ação. Normalmente para riscos classificados com baixa probabilidade e impacto, a ação é de aceitação passiva do risco. Nesta seção é abordada a $4^{\mathrm{a}}$ e a $5^{\mathrm{a}}$ etapas do modelo GROT. São listadas as estratégias de gerenciamento e respostas aos riscos identificados e classificados nas etapas 2 e 3 do modelo, para cada agente.

O risco de mercado/preço tem probabilidade e impacto classificados como médio para o produtor. Como esse risco pode gerar perdas de receitas futuras, com efeito na liquidez, é necessário acompanhamento e compreensão das oscilações de mercado. A resposta ao risco é a mitigação por meio da fixação do preço para minimizar o risco de venda na baixa. Para a Cooperativa e a Trader, a probabilidade de ocorrência e impacto é alto, devido ao preço das commodities serem cotados em bolsa e ter variação diária. O preço tem alta volatilidade, a margem é pequena e qualquer flutuação de preço intraday ou de fechamento para abertura no dia seguinte compromete o resultado. Assim, a ação deve ser de mitigar por meio de hedge das posições assumidas no dia ou trabalhar com volumes casados.

O risco sistêmico para o produtor tem probabilidade baixa e impacto médio. O efeito é a possibilidade de redução de crédito para custeio e investimento. A ação deve ser de mitigação por meio de contratos de troca, além de entregar a safra em empresas com bom histórico de pagamento. Para a Cooperativa e a Trader a probabilidade é baixa, mas o impacto é alto. Isto se dá porque as negociações são realizadas por meio de tradings, que negociam na bolsa de mercadorias e futuros e/ou exportam o produto, com margem reduzida, então a perda de receitas futuras afetam a geração de caixa. Ainda, deve-se considerar que a análise de credito é atualizada, pelo menos uma vez ao ano, por meio dos relatórios contábeis e financeiros da adquirente do crédito. Assim, o que ocorre é que, na média, 90\% das vendas são com recebimento antecipado à retirada do grão. Então, a ação é mitigar o risco, por meio de controle eficaz de cobrança e análise estruturada de crédito. Comparando os três agentes, as entrevistas revelaram que a Trader é a quem está com maior exposição ao risco sistêmico devido ao maior volume que transaciona em 
operações de troca e pelo fato de realizar o pagamento antecipado à retirada do grão, pois no momento da retirada pode ocorrer a não entrega total ou parcial do volume negociado.

O risco de crédito para produtor apresenta baixa probabilidade, mas alto impacto, podendo afetar a continuidade do negócio e causar a falência do produtor. A ação apropriada é de mitigação por meio de contratos. Para a Cooperativa e a Trader a probabilidade também é baixa e o impacto é alto. Para esses dois agentes a ação é mitigar o risco por meio de controles mais eficazes do sistema de cobrança e análises estruturadas de crédito.

Acerca do risco de base, o produtor não percebe muito este risco, pois ele tem um preço de mercado que a cooperativa pratica com maior margem operacional. Assim, a probabilidade e impacto é baixo, tendo como ação aceitar o risco. Mas na Cooperativa e na Trader a probabilidade e o impacto é alto, devido a margem ser pequena e qualquer oscilação influência no resultado. A ação é mitigar o risco com o acompanhamento histórico das oscilações, trabalhando com a média histórica do valor de base, pois não existe hedge para esse valor.

Quanto ao risco cambial, para o produtor a probabilidade e o impacto são baixos, tendo como ação mitigar o risco com contrato, ou seja, fixar o preço do insumo com o preço da commodity. Para a Cooperativa a probabilidade e impacto são baixos, pois as compras e vendas são na mesma moeda, não havendo o seu descasamento porque a cooperativa não realiza exportações há mais de três anos. A ação para a Cooperativa é aceitar o risco. Para a Trader a probabilidade e impacto é médio, pois ela realiza operações de compras em Reais e operações de vendas em Dólar, logo estão vulneráreis as oscilações do mercado e do câmbio. A ação nesse caso é mitigar o risco por meio de hedge financeiro nas operações.

Sobre o risco da taxa de juros a probabilidade e impacto são médios para o produtor, porque em todo ciclo é lançado o Plano Safra, o qual contempla as taxas que serão praticadas pelo governo e valores que serão disponibilizados no mercado. Mas como o Plano Safra pode apresentar oscilações em relação às taxas praticadas no mercado, a ação é mitigar o risco buscando outras fontes de financiamento da safra, como por exemplo a cooperativa por meio de operações com contratos. Por sua vez, para a Cooperativa a probabilidade é alta, devido a política econômica do Brasil estar em um período de instabilidade, mas o impacto é baixo, porque há poucos descasamentos de datas entre a compra e venda. A ação é mitigar o risco, realizando venda casada com a compra. Para a Trader a probabilidade é alta e o impacto é médio, pois ocorre descasamento financeiro. A Trader paga pela commodity para, então, fazer a retirada e embarca-la para exportação. Esse período entre o pagamento e o embarque demora, geralmente, 45 dias. A ação de mitigação nesse caso é buscar financiamento externo, com taxas de juros menores, e contratos de hedge cambial para proteger-se da oscilação da moeda.

O risco de liquidez para o produtor tem baixa probabilidade e impacto médio. Nos últimos anos o agronegócio apresenta boa liquidez e as operações para pagamento dos produtos estão vinculadas a época da colheita. Assim, a ação é mitigar o risco por meio de contratos de troca, realizando as compras de insumos para pagamento na colheita. Para a Cooperativa e para a Trader a probabilidade e impacto são baixos porque as vendas são atreladas com as compras. A ação de aceitação ativa envolve apenas os procedimentos de monitoramento do processo de compra e venda.

$\mathrm{O}$ risco de contrato tem probabilidade baixa e impacto médio para os três agentes. A probabilidade baixa deve-se a experiência, rotina dos agentes e exigência de emissão da CPR na celebração dos contratos. A ação de mitigação envolve o acompanhamento sistemático das lavouras e da colheita por meio da estrutura do departamento técnico agrícola da Cooperativa.

O risco de produção para o produtor tem probabilidade média e impacto alto, devido ao manejo da lavoura e o histórico de produção. A ação de mitigação é por meio da contratação do seguro agrícola. Para a Cooperativa e a Trader a probabilidade e o impacto são médios.A ação de mitigação é realizada por meio do acompanhamento das lavouras e da diversificação da carteira.

Considerando o histórico e devido ao manejo e tecnologia aplicados nas culturas atualmente, os riscos fitossanitários para o produtor tem probabilidade baixa e impacto médio. Porém, cabe ressaltar que quanto menor o produtor, maior é a exposição a este tipo de risco, pois não há como compensar as perdas. 
Para a Cooperativa e para a Trader, devido ao porte, uma perda localizada pode ser compensada por outras culturas ou atividades em regiões que não foram afetadas. Logo tanto a probabilidade quanto o impacto são baixos. A ação é mitigar o risco por meio do acompanhamento das lavouras por técnicos especializados.

Quanto ao risco climático, considerando a área de atuação do produtor, da cooperativa e da Trader e baseado no histórico climático, observou-se que a probabilidade é baixa e o impacto é médio para todos os agentes. Todavia, o efeito climático pode ser mais ou menos notado de acordo com a intensidade da intempérie e o tamanho de área atingida. Em outras palavras, pequenos produtores podem ser mais prejudicados quando o evento de risco climático ocorrer. A ação é aceitar o risco por meio do monitoramento/zoneamento agrícola e escolha de cultivares que se adaptam melhor ao clima/período/região, apoiado pelo departamento técnico agrícola da Cooperativa. O propósito deste monitoramento/zoneamento é minimizar os riscos relacionados aos fenômenos climáticos e permite que cada município identifique a melhor época de plantio das culturas, nos diferentes tipos de solo e ciclos de cultivares. É uma metodologia validada pela Empresa Brasileira de Pesquisa Agropecuária (EMBRAPA) e adotada pelo Ministério da Agricultura.

O risco de controle administrativo para o produtor é baixo quanto a probabilidade e o impacto, pois está relacionado aos controles da Cooperativa. Logo, a ação é aceitar, dado que o produtor associado confia na Cooperativa ao fazer o contrato. A cooperativa e a Trader estão mais sujeitos a esse tipo de risco, devido ao ônus de má fé do colaborador. A ação é mitigar o risco por meio de rotinas, procedimentos e relatórios que inibam e evitem falhas.

Para os agentes o risco de conhecimento técnico em operações de troca tem probabilidade e impacto baixos. A ação de mitigação para o produtor se dá por meio do acompanhamento do mercado, bem como conhecer os riscos e benefícios das operações de troca. Para a Cooperativa e a Trader a mitigação se dá por meio de rotinas, procedimentos e relatórios que inibam e evitem falhas, pois os colaboradores e a Trader conhecem as normas e procedimentos dos contratos.

O risco de pessoal para o produtor é baixo quanto a probabilidade e impacto. A maioria dos produtores possui uma administração familiar de seus empreendimentos. A mitigação do risco envolve melhorar a estrutura de informação e controle familiar. Para a Cooperativa e a Trader a probabilidade e o impacto também são baixos, devido a sua estrutura operacional. A ação é mitigar o risco utilizando rotinas, procedimentos e relatórios que inibam e evitem falhas.

Assim, foi analisada a aplicação do GROT até a quinta etapa. A sexta e sétima etapas, respectivamente, implantar as ações de mitigação dos riscos e acompanhar os riscos e as ações de mitigação, requerem outros processos na Cooperativa, tais como: adaptar o modelo atual ao modelo alternativo (GROT) por meio da divulgação e disseminação, ajustar procedimentos, sistemas, relatórios, entre outros, visando produtores cooperados, Cooperativa e Trader. Essas etapas não foram implementadas pela cooperativa até a finalização dessa pesquisa.

\section{Conclusão}

Este estudo teve como objetivo analisar um modelo de gerenciamento de riscos nas operações de trocas do agronegócio. A avaliação da aderência do modelo aos processos de uma cooperativa agroindustrial permitiu a identificação e análise dos riscos envolvidos nessas operações e suas possíveis estratégias de respostas, considerando as perspectivas do produtor cooperado, da Cooperativa e da Trader. Ao longo da análise da aplicação do modelo GROT (Gestão de Riscos em Operações de Troca), que contemplou a identificação e análise dos riscos e suas estratégias de gestão considerando os agentes envolvidos nas operações - o produtor que é fornecedor das commodities e comprador de insumos e a Trader, com quem a Cooperativa opera para escoar o produto agrícola - foi possível verificar que os colaboradores entrevistados ampliaram a compreensão do que é gerenciamento de riscos. Essa ampliação de entendimento contrastou com a dificuldade inicial de entender a importância e a potencial contribuição de uma perspectiva mais detalhada de gestão de riscos. Foi possível verificar que a Cooperativa possui um modelo de gerenciamento de riscos institucionalizado, internalizado entre os colaboradores envolvidos com os contratos de operações de troca e estes com compreensão macro, ou seja, em grandes grupos de riscos (mercado, produção, contrato, 
sistêmico e cambial), para os quais tem medidas de gerenciamento, mas sem analisar a probabilidade de ocorrência e o impacto.

Com relação aos produtores, observou-se que eles sabem o que é contrato de troca e os potenciais riscos e os benefícios, mas também de modo bastante agregado e menos aprofundado, quando comparado com os colaboradores da Cooperativa. $\mathrm{Na}$ fase de entrevistas foram verificadas as dificuldades de entendimento dos processos de gerenciamento dos riscos nas operações. Isto demonstra que a Cooperativa pode desenvolver planos de capacitação juntos aos produtores cooperadores sobre contratos de troca e gerenciamento de riscos. Ou seja, junto aos produtores cooperados é oportuno realizar cursos de capacitação sobre contratos de trocas e gerenciamentos de riscos, porque eles são promotores de riscos em algumas situações e, em outras, estão suscetíveis a riscos causados por outro agente.

A Trader, por sua vez, tem maior domínio da dinâmica das operações de troca, mas a perspectiva de compreensão de detalhamento dos riscos assemelha-se aos dos colaboradores da Cooperativa. Assim, também houve uma dificuldade inicial em entender a segregação dos riscos. Mas essa dificuldade foi superada ao longo da pesquisa.

Ao término deste estudo conclui-se que o atual modelo de gerenciamento de riscos das operações de troca na Cooperativa atende parcialmente as necessidades atuais, pois carece de um mapeamento mais detalhado e sistemático dos riscos e das estratégias de respostas. Os aprimoramentos sugeridos compreendem a segregação dos riscos (mapeamento) e a análise bidimensional por meio de uma matriz de risco, que considera a probabilidade de ocorrência e o seu impacto no resultado e/ou na estratégia da Cooperativa. A disseminação e a compreensão dos conceitos e categorizações dos riscos pelos envolvidos, nas mais diversas áreas da Cooperativa, e entre produtores e Trader, se fazem necessárias para que haja melhorias na gestão de riscos.

\section{Referências}

ABNT NBR ISO 31000, de 2018. Gestão de riscos - princípios e diretrizes. São Paulo: Associação Brasileira de Normas Técnicas, 2018.

BELIK, W. O financiamento da agropecuária brasileira no período recente. Texto para discussão n. 2028. Instituto de Pesquisa Econômica Aplicada (IPEA), Brasília, 2015.

BRASIL. Ministério da Agricultura. Plano agrícola e agropecuário 2016/17. Brasília, 2016. Disponível em: http://www.agricultura.gov.br/pap. Acesso em: 24 mar. 2017.

BORGERTH, V. M. C. Sox: Entendendo a Lei Sarbanes - Oxley. Rio de Janeiro: Thomson, 2006.

CHING, H. Y. Contribuição das boas práticas do mercado para eficiência na gestão de risco corporativo.

Revista Brasileira de Estratégia, v. 4, n. 3, p. 257-273, 2011.

CHING, H. Y.; COLOMBO, T. M. Boas práticas de gestão de risco corporativo: estudo de dez empresas. Revista Brasileira de Estratégia, v. 6, n. 1, p. 23-35, 2013.

COSO. Committee of Sponsoring Organizations of the Treadway Commission. Gerenciamento de riscos corporativos: estrutura integrada. (2007). Disponível em: https://www.coso.org/Documents/COSO-ERMExecutive-Summary-Portuguese.pdf. Acesso em: 24 mar. 2018.

DAMODARAN, A. Gestão estratégica do risco: uma referência para a tomada de riscos empresariais. Porto Alegre: Bookman, 2009.

DIAS, S. V. S. Auditoria de Processos Organizacionais. 2 ed. São Paulo: Atlas, 2008.

DIAS, S. V. S. Manual de Controles Internos. São Paulo: Atlas, 2010.

FAMÁ, R.; CARDOSO, R. L.; MENDONÇA, O. Riscos financeiros e não financeiros: uma proposta de modelo para finanças. Cadernos da FACECA, Campinas, v. 11, n. 1, 33-55; Jan./Jun., 2002. 
IFAC, International Federation of Accountants. Enhancing shareholder wealth by better managing business risk. New York: IFAC, 1999.

LOYOLA, P.; MOREIRA, V. R.; VEIGA, C. P. Analysis of the Brazilian Program of Subsidies for Rural Insurance Premium: evolution from 2005 to 2014. Modern Applied Science, v. 10, n. 7, p. 87-98, 2016. Disponível em: http://ccsenet.org/journal/index.php/mas/article/view/55796. Acesso em: 30 jul. 2017.

MARTINS, G. A. Estudo de caso: uma estratégia de pesquisa. São Paulo: Atlas, 2006

MOREIRA, V. R.; SOUZA, A.; DUCLÓS, L. C. Avaliação de retornos e riscos na comercialização do milho: estudo de caso usando value-at-risk. Revista de Economia e Sociologia Rural, Brasília, DF, v. 52, n. 2, p. 303-322, 2014.

MOREIRA, V. R.; FREIER, A.; VEIGA, C. P. A review of concepts, strategies and techniques management of market risks in agriculture and cooperatives. International Business Management. V. 10, n. 6, 739-750, 2016.

MOREIRA, V. R.; KURESKI, R.; VEIGA, C. P. Assessment of the economic structure of Brazilian agribusiness. The Scientific World Journal, v. 2016, 2016. Disponível em: https://www.hindawi.com/journals/tswj/2016/7517806/. Acesso em: 18 jul. 2017.

OZAKI, V. A. O papel do seguro na gestão do risco agrícola e os empecilhos para o seu desenvolvimento. Revista Brasileira de Risco e Seguro, Rio de Janeiro, v. 2, n. 4, p. 75-92, out./mar. 2007.

PADOVEZE, C. L.; BERTOLUCCI, R. G. Gerenciamento do Risco Corporativo em Controladoria: Enterprise Risk Management (ERM). 2 ed. São Paulo: Atlas, 2013.

PARANÁ COOPERATIVO. Financiamento agrícola: LCA ganha peso na estratégia de crédito do governo federal. Informe Paraná Cooperativo. 2016. http://www.paranacooperativo.coop.br/ppc/index.php/sistema-ocepar/comunicacao/2011-12-07-11-0629/ultimas-noticias/109308-financiamento-agricola-lca-ganha-peso-na-estrategia-de-credito-do-governofederal. Acesso em: 24 mar. 2017.

SILVA, F. P. Financiamento da cadeia de grãos no Brasil: o papel das tradings e fornecedores de insumos (Dissertação de mestrado). Universidade Estadual de Campinas, Instituto de Economia, Campinas, SP, Brasil. 2012. Disponível em: http://repositorio.unicamp.br/handle/REPOSIP/286009. Acesso em: 23 mar. 2018. 